\title{
Responsible management of motor vehicle drivers with dementia
}

\author{
${ }^{1} \mathrm{M}$ Yates, ${ }^{2} \mathrm{JE}$ Ibrahim \\ ${ }^{1}$ Consultant Physician in Geriatric Medicine, Lead Clinician Memory Clinic and Director of Clinical Studies, Deakin University, Ballarat \\ Health Services, Australia; ${ }^{2}$ Research Fellow, Prevention Research Unit, Department of Forensic Medicine, Monash University, Melbourne, \\ Australia and Consultant Physician in Geriatric Medicine, Clinical Director Sub-Acute Services, Ballarat Health Services, Australia
}

ABSTRACT When Bridget Driscoll, a 44-year-old mother of two died after being struck by a motor vehicle, considered to be the first motor vehicle fatality in UK and possibly the world, the coroner stated 'I trust this sort of nonsense will never happen again'.' Sadly, the coroner, medical practitioners and general public would be deeply and repeatedly disappointed. It was 1896. Motor vehicles were a curiosity. Drivers did not undergo any form of testing, be it medical fitness, driving ability or otherwise, and there were no licensing regulatory agencies. By 2010 , road injury was the ninth most common cause of death globally ( 1.3 million deaths per annum) and dementia the fourth most common in high income countries. ${ }^{2}$ By 2030 the number of all licensed UK drivers who are 65 years or older will increase by almost $50 \%$ to almost one in every four drivers. ${ }^{3}$ If the juxtaposition of driving with dementia in an ageing population is not already a contentious social, political and medical issue, it certainly will become so.

KEYWORDS Driving, dementia, ageing, physician's role, clinical assessment

DECLARATIONS OF INTERESTS Dr Yates reports funding for travel to coordinate and attend the National Driving and Dementia workshop sponsored by the Australian Government Minister's Dementia Advisory Group, August 2013.

\author{
Correspondence to $M$ Yates \\ Deakin Clinical School \\ Ballarat Health Services \\ Drummond St North \\ Ballarat 3350 \\ Australia
}

e-mail marky@bhs.org.au

\section{HEALTHY AGEING}

To achieve healthy ageing as a global public health goal ,individuals need to maintain their mobility within their community. ${ }^{4}$ This is only possible with viable transport options that include driving. Public transport is infrequently used by people aged 65-75 years, and the longer the trip, the more likely a private car will be taken. ${ }^{5}$

Older people are increasing as a proportion of road users, are more likely to have dementia and are overrepresented in fatal and serious crashes. ${ }^{6}$ Achieving healthy ageing therefore has the potential to undermine our ability to maintain one of the ten great public health achievements of the twentieth century, that is, the significant reduction in motor vehicle-related deaths. ${ }^{7}$ Motor vehicle safety has improved due to our combined efforts addressing vehicle engineering, safer roads, driver ability and behaviours (e.g. the use of seat belts, drink driving). Further improvements in all these areas would make driving safer even for people with dementia.

\section{DRIVING WITH DEMENTIA}

It is not surprising there are discordant views about if and when older drivers should cease driving, especially if diagnosed with dementia. There is also an emerging debate about who is responsible for these decisions, and how they are made should be made. The existing research evidence base raises more questions than answers.

The most recent Cochrane Review of driving assessment for maintaining mobility and safe driving with dementia concludes 'there is no randomised evidence to indicate whether neuropsychological, on-road or other assessment of driving ability can help support safe drivers remain mobile, or to reduce crashes'. ${ }^{8}$ If we accept a 'community road safety first' argument and stopped all patients with dementia (irrespective of severity) from driving, in the parlance of 'number needed to treat', for every six crashes that were prevented, I 2 I people who would not have had a crash would also have been stopped from driving. ${ }^{8}$ However, in most developed countries, the ability to drive is a cultural statement of vitality and the possession of a licence critical to personal identity. Many of the people who had to stop driving would find it an unacceptable approach; this is evident in our patients, referred for cognitive assessment and diagnosis who fear losing permission to drive.

Perhaps our ageing society is willing to take more risk as a whole than medical practitioners. We practise medicine in order to restore health and protect from harm. It is widely accepted that some people with early dementia are safe to drive and driving is important for well-being. An enlightened society perhaps considers the injustice 
of removing a person's licence unnecessarily to be more important than the potential risk of harm (of having people with dementia continuing to drive). Consider the example of how countries determine the blood alcohol levels for drivers; these range from $0 \%$ to $0.08 \%$ and imply a measure of the risk appetite in those communities.

\section{THE ROLE OF PHYSICIANS}

And here we sit as physicians on the horns of several dilemmas. What is the role of the physician in this emotionally charged debate? How do we assist our patients and their families to deal with this complex issue? How do we achieve an acceptance of the decision to drive or not? Do we advocate for community safety in the absence of research evidence and stop all people with dementia from driving? Or do we advocate for maintaining the rights of an individual and support continuing to drive because of its significant emotional context and impact on well-being? Several factors must be considered.

First, provide the patient with an understanding of their specific risks of driving. This requires identifying the nature and degree of the cognitive impairments associated with their dementia in the context of any additional physical limitations and visual impairment. Generalities do not serve the patient well.

Older people, because of their frailty, are more likely to die than younger drivers in a motor vehicle crash. Fatalities per distance driven is higher in those aged 70 years and older compared to 18-24 year olds. ${ }^{9}$ Based on overall crash occurrences per year, older drivers have fewer crashes than younger drivers, largely owing to a reduction in driving miles. ${ }^{10}$ However, when matched for driving distance per annum, most drivers aged 75 years and above were safer than all other drivers." The absolute crash rates in older people are very low, only one-third of the rate in younger drivers (600 and I,934 per 100 million person-trips respectively). ${ }^{12}$

Age is not a predictive factor of an increased crash risk, however the presence of dementia is associated with a two to five times greater crash rate than aged-matched controls. $^{10}$ The risk of crashing for a driver with Alzheimer's disease rises above that of teenage males after three years post-disease onset. ${ }^{13}$ Specific crash rate data is lacking for other causes of dementia. However, impairments of insight, attention and problem solving seen in fronto-temporal dementia and the visuospatial difficulties in Lewy body disease would be likely to lead to earlier driving cessation

Second, ascertain the extent and domains of cognitive change as these relate to driving. The evidence on clinical assessments of driving ability remains equivocal at least in early dementia. There is extensive literature addressing the question of driving assessment and competence. However, there is little agreement on what is best practice in the setting of dementia. ${ }^{14}$ Screening all older drivers remains controversial. The gold standard of on-road assessment is expensive and lacks an accepted criteria, with considerable variation in terms of vehicles, routes and tasks. ${ }^{8}$ There are a myriad of office-based tests and suites of tests, none of which have enough clinical research evidence to make specific recommendations. The published research has investigated cognitive measures, measures of behavioural response to driving and carer/family impression, but as yet cannot provide any recommendations for office-based tools to define safe or unsafe driving.

Some advocate for office-based testing, such as Trails B (assesses attentional switching) as a method for triaging those patients requiring referral for more detailed assessment. This could be useful in environments where access to on-road assessment is limited by expense or availability. $^{15}$ Others suggest the Maze Test (assesses planning, executive and visuospatial function) as a useful clinical guide to the risk of driving with dementia or the Useful Field of Vision (computer-based test of visual scanning and attention), but this is of limited practical utility as it requires highly specialised equipment. ${ }^{16}$

Third, recognise that the skills for safe driving will vary with age, cognition and driving conditions. Safety is a matrix of conditions such as traffic complexity, driver fatigue, road conditions and weather that are not constant between settings or patients. For example, the differences between driving on freeways and in metropolitan areas as opposed to rural roads and regional areas are profound and amplified in dark and rainy conditions.

Fourth, understand that withdrawal from driving has significant adverse consequences for the patient. For any person this is associated with losses of self-esteem, identity and confidence. In persons with dementia it is associated with risk of social disengagement, a higher risk of pedestrian injury and potentially avoidance of medical care. It has also been associated with earlier entrance to nursing home care. ${ }^{17}$ Older patients require transport mobility to meet their healthcare needs and unnecessary restriction will have deleterious effects on their independence. A survey of non-drivers in Victoria, Australia, reported that a lack of transport alternatives resulted in at least half of the surveyed 225 non-driver older people foregoing social events and opportunities to visit family and friends. ${ }^{18}$

Fifth, the majority of older people reduce the complexity of their driving journeys or cease on their own accord. ${ }^{19}$ So a compassionate approach is not necessarily dangerous. 
Women are more likely to self-regulate than men. ${ }^{20}$ Some people with dementia, depending on their level of insight, will choose to stop driving or self-regulate and limit where and when they drive. ${ }^{21}$ The Dubinsky et al. (1992) study of 67 people with dementia compared to 100 controls found the majority $(67 \%)$ had ceased voluntarily or with family insistence. ${ }^{22}$

Sixth, an overly officious approach to this aspect of living with dementia may create the inadvertent consequence of deterring people from seeking medical advice for early diagnosis. Up to a third of family members and people with dementia found that driving withdrawal had a much greater impact on them than expected. ${ }^{18,23}$ As legislation moves to a more publicised and rigid approach to driving with dementia this may deter families and people with cognitive symptoms from seeking a timely diagnosis.

Patients with dementia and family care-givers overwhelmingly prefer their general practitioner or medical specialist be the one to tell the person to cease driving. ${ }^{21}$ This does not make the task easy, nor does it dissipate the feelings of anger, confusion and depression. The issue of driving is emotionally charged and there are real risks that a rigid approach to licence withdrawal will damage the doctor-patient relationship and reduce willingness to access healthcare, leading to poorer health outcomes.

Seventh, context in evaluating risks and benefits is vital. This requires understanding and balancing the biopsychosocial model of healthcare for the individual, alongside public health for the population and the values of society as a whole. The use of public transport is not as accessible for older people with co-morbid conditions that cause physical or functional disability. The impact of restricting patients residing in rural and regional areas is substantially different to those living in metropolitan areas, and rural settings often have fewer hazards to negotiate while driving. The risk to others in the population exposed is much smaller in a rural setting and the availability of alternative transportation is much more limited.

\section{CONCLUSION}

Our listing of factors to consider may help. However, the most important role the physician has is engaging in this debate. Remaining a passive observer when there is a policy vacuum with a limited research evidence base and a popular media that continue to highlight older drivers as unsafe is not consistent with contemporary clinical leadership. If we continue to stand silent, we do so to the detriment of people with dementia. Our choices are plain, though perhaps unpalatable. In the absence of a robust evidence base demonstrating substantial harm we should accept the responsibility and risk as a medical practitioner to navigate and support our patients through this difficult situation, much as one would in discussing the use of warfarin in atrial fibrillation, but with the added complication that some of the potential adverse effects will be felt by a third party and not the patient alone. At times we will get it right and other times horribly wrong, but our decision-making process should be transparent, rational and individualised. Alternatively we could support an individual's rights and responsibility to make this decision by themself, accepting that the person with dementia and their family may be best placed to balance the potential risks.

Until we have driverless cars, or robust clinical trial data, how we deliberate and approach the decision about where we draw the line for driving with dementia will be a reflection of our maturity as a physician serving our society. Be aware that you are not passively contributing to a nanny state for grannies.

Joseph Ibrahim has also contributed to an educational video on this topic, available on Youtube (www.youtube. com/watch? $v=4 \mathrm{~F} 9 \mathrm{z} 8 \mathrm{mPhcTw}$ ) 


\section{REFERENCES}

I Roberts I. Reducing road traffic. BMJ 1998; 316:242-3. http:// dx.doi.org/l0.1/36/bmj.316.7I27.242

2 World Health Organization. The top 10 causes of death in the world, 2000 and 2011 [Internet]. Switzerland:WHO; 2013 [cited 20I4 Jan 3]. Available from: http://www.who.int/mediacentre/factsheets/ fs3 I0/en/index.html

3 Organisation for Economic Co-operation and Development (OECD). Ageing and transport: mobility needs and safety issues. Paris: OECD; 201 I [cited 2014 Jan 22].Available from: http://www.oecd. org/sti/transport/roadtransportresearch/2675I89.pdf

4 Edwards JD, Lunsman M, Perkins $M$ et al. Driving cessation and health trajectories in older adults.J Gerontol A Biol Sci Med Sci 2009; 64:I290-5. http://dx.doi.org/I0.I093/gerona/glpI I4

5 Alsnih R, Hensher DA. The mobility and accessibility expectations of seniors in an aging population. Transportation Research Part $A$ Policy and Practice 2003; 37:903-16. http://dx.doi.org/I0.1016/ S0965-8564(03)00073-9

6 Langford J, Andrea D, Fildes B et al. Assessing responsibility for older drivers' crashes. Austroads Project RS.UB.507. Sydney,Australia; 2005

7 Ten great public health achievements: United States, 1900-1999. MMWR Morb Mortal Wkly Rep 1999; 48:24I-3.

8 Martin AJ, Marottoli R, O'Neill D. Driving assessment for maintaining mobility and safety in drivers with dementia. Cochrane Database Syst Rev 2013; 8:CD006222. http://dx.doi. org/I0.I002/I465I858.CD006222.pub4

9 Mayhew DR, Simpson HM, Ferguson SA. Collisions involving senior drivers: high-risk conditions and locations. Traffic Inj Prev 2006; 7: I 17-24. http://dx.doi.org/10.1080/15389580600636724

10 Ott BR, Daiello LA. How does dementia affect driving in older patients? Aging Health 2010; 6:77-85. http://dx.doi.org//0.2217/ ahe.09.83

I I Langford J, Methorst R, Hakamies-Blomqvist L. Older drivers do not have a high crash risk: a replication of low mileage bias. Accid Anal Prev 2006; 38:574-8. http://dx.doi.org/l0.1016/j. aap.2005.12.002

12 Leproust S, Lagarde E, Salmi LR. Systematic screening for unsafe driving due to medical conditions: still debatable. BMC Public Health 2008; 8:27. http://dx.doi.org/I0.I I86//47I-2458-8-27
I3 Drachman DA, Swearer JM. Driving and Alzheimer's disease: the risk of crashes. Neurology 1993; 43:2448-56. http://dx.doi. org/10.1212/WNL.43.12.2448

I4 Charlton JL, Koppel S, Odell M et al. The influence of chronic illness on crash involvement of motor vehicle drivers. 2 nd edition. Australia: Monash University Accident Research Centre; 2010.

I5 Roy M, Molnar F. Systematic review of the evidence for Trails B cut-off scores in assessing fitness-to-drive. Can Geriatr J 20l3; 16:120-42.

16 Classen S, Wang Y, Crizzle AM et al. Predicting older driver on-road performance by means of the useful field of view and trail making test Part B. Am J Occup Ther 2013; 67:574-82. http://dx.doi. org/10.50I4/ajot.2013.008136

17 Freeman EE, Gange SJ, Munoz B et al. Driving status and risk of entry into long-term care in older adults. Am J Public Health 2006; 96:I254-9. http://dx.doi.org/I0.2105/AJPH.2005.069/46

I8 Royal Automobile Club of Victoria. Stranded: experiences of nondrivers in Victoria [Internet].Victoria: RACV; 2009 [cited 2014 Jan 4]. Available from: http://www.racv.com.au/wps/wcm/connect/823864 8040af3a768dd4dd742e6b4ca9/Stranded+Experiences+of+nondrivers+in+Victoria+2009.pdf?MOD=AJPERES\&CACHEID=82386 48040af3a768dd4dd742e6b4ca9

19 Neitch SM, Madero G, Maynard S. Driving assessment results in patients with a diagnosis of dementia. WV Med J 20I I; 107:54-8.

20 Kostyniuk LP, Molnar LJ. Self-regulatory driving practices among older adults: Health, age and sex effects. Accident Anal Prev 2008; 40:1576-80. http://dx.doi.org//0.1016/j.aap.2008.04.005

21 Alzheimer's Australia NSW. Driving and dementia in New South Wales. Discussion Paper I, April 2010 [Internet]. NSW:Alzheimer's Australia NSW; 2010 [cited 2014 Jan 4]. Available from: http:// www.abc.net.au/radionational/linkableblob/5 I 23364/data/drivingand-dementia-in-nsw-data.pdf

22 Dubinsky RM, Williamson A, Gray CS et al. Driving in Alzheimer's disease. J Am Geriatr Soc 1992; 40: I I I2-6.

23 Alzheimer's Australia Victoria. Driving and dementia in Victoria. Discussion Paper 2013 [Internet]. Victoria: Australia; 2013 [cited 2014 Jan 22]. Available from: http://www.fightdementia.org.au/ common/files/VIC/Dementia_and_Driving_20I3.pdf 